\title{
Durability of transcatheter aortic valves, current evidence and future prospective
}

\section{Giorgio Marengo, Edoardo Elia, Francesco Bruno, Luca Franchin, Francesco Piroli, Ovidio De Filippo, Federico Conrotto, Gaetano Maria De Ferrari, Fabrizio D’Ascenzo}

Division of Cardiology, Cardiovascular and Thoracic Department, Città della Salute e della Scienza Hospital and University of Turin, Turin 10126, Italy.

Correspondence to: Dr. Giorgio Marengo, Division of Cardiology, Cardiovascular and Thoracic Department, Città della Salute e della Scienza Hospital and University of Turin, Turin 10126, Italy. E-mail: giorgio.marengo@edu.unito.it

How to cite this article: Marengo G, Elia E, Bruno F, Franchin L, Piroli F, De Filippo O, Conrotto F, De Ferrari GM, D'Ascenzo F. Durability of transcatheter aortic valves, current evidence and future prospective. Vessel Plus 2021;5:12.

http://dx.doi.org/10.20517/2574-1209.2020.58

Received: 19 Oct 2020 First Decision: 23 Nov 2020 Revised: 28 Nov 2020 Accepted: 18 Jan 2021 Published: 12 Mar 2021

Academic Editor: Maurizio Taramasso Copy Editor: Yue-Yue Zhang Production Editor: Xi-Jun Chen

\begin{abstract}
Transcatheter aortic valve implantation (TAVI) has become a safe and valid procedure in all surgical risk patients, expanding TAVI indications to a larger number of patients. However, while short- and mid-term follow up showed similar results compared to surgery, long-term durability remains unstudied. Concerns about TAVI longevity are mainly raised by early development of higher rates of bioprosthetic valve disfunction (BVD) and especially of paravalvular leaks (PVL), which have been previously related with long-term mortality. In this context, the definition of BVD, its relationship with the TAVI technology (balloon vs. self-expandable), and the prognostic role of mild PVL are a complex topic which has not been clarified yet, along with outcomes of valve-in-valve (ViV) intervention, which represents a valid therapeutic option in the case of severe BVD. The aim of this narrative review is to offer a general overview of the evolution of TAVI indications; show the differences between balloon and self-expandable prostheses performances; clarify the definition, classification, and prognostic role of BVD; and summarize current evidence about long-term TAVI durability.
\end{abstract}

Keywords: Aortic stenosis, transcatheter aortic valve implantation, TAVI durability, bioprosthetic valve degeneration, transcatheter aortic valve in valve 


\section{INTRODUCTION}

Since its introduction, TAVI has rapidly evolved to become a solution for patients with symptomatic aortic stenosis at high or intermediate risk of surgery ${ }^{[1-4]}$. The rapid technological improvement of transcatheter prostheses and the progressive skill acquisition in operators significantly improved TAVI performance, expanding this type of intervention to a larger number of patients ${ }^{[5]}$. In 2019, two randomized controlled trials ${ }^{[6,7]}$ showed non-inferiority of TAVI compared with surgical aortic valve replacement (SAVR) also for patients with low surgical risk. However, these results were limited by the short-term follow up, raising concerns about transcatheter prostheses durability, also considering the younger age and the higher life expectancy of recipients. According to several trials, TAVI platforms are related at mid-term follow-up with higher degrees of non-structural valve deterioration (NSVD) when compared with SAVR, mainly due to the higher percentage of paravalvular leaks $(\mathrm{PVL})^{[6-9]}$. In addition, if a negative prognostic impact of moderate and severe PVL is well known, the long-term impact of mild PVL is still unclear, and whether PVL is related or simply associated with mortality in low-risk patients with symptomatic aortic stenosis remains to be demonstrated ${ }^{[10,11]}$.

Another challenging point in this context is the choice between balloon-expandable (BE) and selfexpandable (SE) prostheses. Recent data from two large multicenter observational registries ${ }^{[9,12]}$ show better outcomes of BE compared to SE prostheses in terms of cardiovascular mortality and moderate PVL, but these findings could be biased since worse anatomical features and more extensive valve calcification are more frequent in SE prostheses candidates, defining baseline more complicated patients.

This change of the epidemiological scenario implies higher relevance of long-term durability, the right choice of the prostheses platform and the need of therapeutic option for severe structural valve deterioration (SVD), especially for younger and low-risk patients, whose life expectancy exceeds valve durability.

The aim of this narrative review is to summarize the available data on long-term durability of TAVI prostheses, according to the type of valve, and highlight the prognostic role and the therapeutic options of structural and non-structural valve deterioration.

\section{EVOLUTION OF TAVI INDICATIONS}

In the last ten years, the spectrum of TAVI candidates has been progressively extended, and, nowadays, TAVI platforms are implanted in all elderly patients independently of surgical risk [Figure 1].

Initially, only high surgical risk patients were suited for TAVI, with a mean age of 80 years old and relevant cardiac and non-risk factors leading to a risk of CV death of about $14 \%$ at one year ${ }^{[1,2,13-16]}$. A few years later, TAVI platforms were also tested in intermediate surgical risk patients (mean age 79 years old), with encouraging results after two years of follow-up ${ }^{[3,4]}$.

The first all-comers randomized controlled trial (RCT) to compare TAVI (with first generation SE prosthesis) and SAVR in patients $>70$ years old independently from surgical risk was the NOTION trial, published in 2015. In this study, the mean age was 79.1 years and the mean society of thoracic surgeons (STS) score was $3 \%$, with $81 \%$ of the patients considered at low surgical risk. No differences were found regarding both a composite outcome of all-cause mortality, stroke, and myocardial infarction $(13.1 \%$ in TAVI patients $v s .16 .3 \%$ in SAVR ones, $P=0.43)$ and CV death $(4.3 \% v s .7 .5 \%, P=0.25)$ after one year of follow-up ${ }^{[17]}$. Remarkably, these results were confirmed at five years $(38 \% v s .36 .3 \%, P=0.86)$, although the sample size was not powered enough to detect clinical difference at long-term follow up ${ }^{[18]}$. 


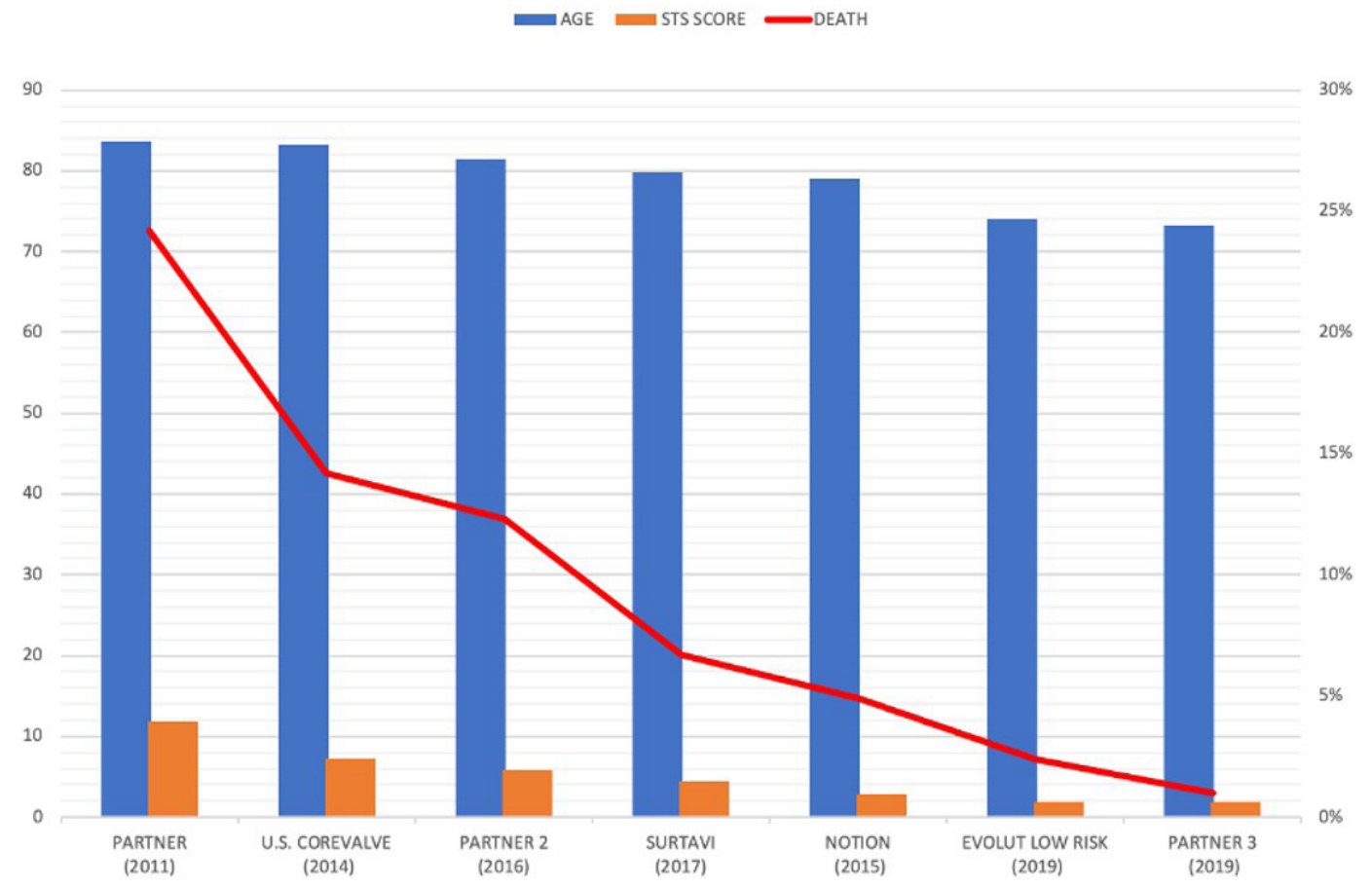

Figure 1. Progressivw reduction of STS score, age and mortality in patients implanted with TAVI. STS: Society of Toracia Surgeons; TAVI: transcatheter aortic valve implantation.

These promising results carried operators to test TAVI platforms also for specific low surgical risk cohorts, and two main RCTs were published on this matter in 2019.

In the Evolut Low Risk trial, 1468 patients with severe aortic stenosis (AS) (mean age 74 years, mean STS $1.9 \%$ ) were randomly assigned to receive TAVI with latest generation SE devices or SAVR. At 30 days, mortality was similar between the two cohorts $(0.5 \%$ vs. $1.3 \%)$. TAVI was associated with higher risk of permanent pacemaker implantation (PPI) and a lower incidence of disabling stroke, although this finding was not confirmed after an extended follow-up, stressing the relevant periprocedural impact of surgical complications. The rehospitalization rate was significantly reduced in TAVI after one year of followup $(3.2 \% v \text { s. } 6.5 \%)^{[7]}$. At two years, the primary composite endpoint (death and disabling stroke) did not significantly differ between TAVI and SAVR (5.3\%vs. 6.7\%, $P>0.99)$.

In the same year, the PARTNER 3 trial randomized 1000 patients (mean age 73 years, mean STS $1.9 \%$ ) to receive TAVI with newer generation BE valve or SAVR. After one year of follow-up, mortality rates were similar between the two groups ( $1 \%$ for TAVI, $2.5 \%$ for SAVR), and BE prostheses met both the noninferiority and superiority criteria compared with SAVR (8.5\% vs. $15.1 \%, P=0.001)$ regarding the primary composite endpoint of death, stroke, and rehospitalizations. No differences in PPI were observed ${ }^{[6]}$. However, this slight superiority observed for BE valves could be caused by a difference in the primary endpoint definition between the two trials: rehospitalization rates were similar in both studies, but they were not included in the primary endpoints in the Evolut Low Risk trial, whereas they mainly drove TAVI superiority in PARTNER 3.

Patients with bicuspid or non-calcific aortic valve, another severe concomitant valvulopathy, and a left ventricular ejection fraction of $<30 \%$ were excluded from all these trials, and the transfemoral approach, which is related to better outcomes compared to other approaches ${ }^{[19]}$, was used in almost all low surgical risk patients. 
Additional data regarding performances of TAVI in low surgical risk populations are provided by several registries. A retrospective Finnish registry published in 2019 compared in a propensity matching analysis severe AS patient with low surgical risk $(<3 \%)$, receiving TAVI or SAVR from 2008 to 2017. After three years of follow-up, overall survival was similar between the two groups (85.7\% TAVI, 87.7\% SAVR, $P=0.45)^{[20]}$. These findings were in contrast with the results of the OBSERVANT registry, which showed, in similar patients, a better survival with SAVR compared with TAVI ${ }^{[2,22]}$. In the OBSERVANT registry, however, patients were enrolled from 2010 to 2012, when operator experience was limited, and only first-generation devices were used, whereas more than $85 \%$ of patients in the Finnish registry received third-generation transcatheter prosthesis.

Longer-term follow-ups have recently been published in some small observational registries ${ }^{[23-25]}$. Only high surgical risk patients (mean STS $>8$ and mean age $>80$ years old) were included, and they were all implanted with first-generation valves. Mortality exceeded $70 \%$ at eight years, but, in surviving patients, very low rates of bioprosthetic valve failure (BVF) and SVD were observed, with more than $95 \%$ of freedom from BVF at eight years ${ }^{[23,25]}$.

In summary, in this 10-year TAVI experience, a significant reduction in mean age and surgical risk of patients was observed, reflecting in lower mortality and rehospitalization rates across trials and registries. Compared with patients enrolled in the PARTNER trial, patients of PARTNER 3 are ten years younger, with almost ten points lower STS score and fewer comorbidities.

These epidemiological differences, along with a progressive technological improvement of the platforms and the acquisition of more operator expertise, determined a significant reduction of mortality, which lowered from $24.2 \%$ to $1 \%$ at one year.

However, while non-inferiority to SAVR could be acceptable for elderly patients with high surgical risk, reduced life expectancy, and various comorbidities, for younger and healthier patients, whose life expectancy should exceed TAVI prostheses durability, it might not be enough.

For that reason, prospective long-term follow-up data in low surgical risk patients are needed to assess the durability of TAVI devices, which has become a crucial endpoint in today's transcatheter approach to severe aortic stenosis.

\section{BALLOON VS. SELF EXPANDABLE VALVES}

The choice between BE and SE prostheses has become increasingly challenging in the last years. These devices indeed have been compared head-to-head in a small number of RCTs, most of them without adequately powered sample size and long-term follow-up, showing discordant results.

Latest generation BE platforms (Sapien 3, Edwards Lifescience) have been compared with SE ones (Evolut $\mathrm{R}$, Medtronic Inc) in the SOLVE-TAVI randomized controlled trial ${ }^{[26]}$. In total, 447 patients were enrolled, and, after 30 days of follow up, equivalence criteria were met for the primary composite outcome of allcause mortality, stroke, and moderate/severe regurgitation; PPI (28.4\% with SE valves vs. $25.9 \%$ with BE valves); its single components; and paravalvular leak rates.

In the previously published CHOICE trial, 241 patients were randomized to receive first generation $\mathrm{BE}$ prostheses (Edwards Sapien XT) or SE prostheses (Medtronic CoreValve). At 30 days, CV mortality, major bleedings, and vascular complications were not significantly different, but BE prostheses showed lower rates of PPI, lower more-than-mild aortic valve regurgitations $(4.1 \% v s .18 .3 \%, P=0.01)$, and less frequent need of implant of more than one prostheses, compared with SE ones ${ }^{[2]}$. These results were not confirmed 


\begin{tabular}{|c|c|c|c|c|}
\hline \multicolumn{5}{|c|}{ Comparison between BE and SE TAVI } \\
\hline Study ID (year) & Design & Mean FU & Sample & Results \\
\hline Choice (2014) & RCT & 30 days & 241 & $\begin{array}{l}\text { Equivalence (BE vs. SE) for: } \\
\text { CV death ( } 41 . \% \text { vs. } 4.3 \%, P=0.99) \\
\text { Bleeding and vascular complications }(18.2 \% \text { vs. } 32.1 \%, P=0.42) \\
\text { BE TAVI associated with lower incidence of: } \\
\text { PPI }(17.3 \% \text { vs. } 37.6 \%, P=0.001) \\
\text { Residual more-than-mild AR }(4.1 \% \text { vs. } 18.3 \%, P<0.001) \\
\text { Need for implanting more than } 1 \text { valve }(0.8 \% \text { vs. } 5.8 \%, P=0.03)\end{array}$ \\
\hline Choice (2020) & RCT & 5 years & 241 & $\begin{array}{l}\text { Equivalence (BE vs. SE) for: } \\
\text { All cause death }(53.4 \% \text { vs. } 47.6 \%, P=0.38) \\
\text { CV death }(31.6 \% \text { vs. } 21.5 \%, P=0.12) \\
\text { Strokes }(17.5 \% \text { vs. } 16.5 \%, P=0.73) \\
\text { Re-hospitalization for HF }(28.9 \% \text { vs. } 22.5 \%, P=0.75) \\
\text { BVF }(4.1 \% \text { vs. } 3.4 \%, P=0.63)\end{array}$ \\
\hline $\begin{array}{l}\text { Solve TAVI } \\
\text { (2020) }\end{array}$ & $\mathrm{RCT}$ & 30 days & 447 & $\begin{array}{l}\text { Equivalence (SE vs. BE) for: } \\
\text { All-cause death }(3.2 \% \text { vs. } 2.3 \%, P \text { equivalence }<0.001) \\
\text { Stroke }(0.5 \% \text { vs. } 4.7 \%, P \text { equivalence }=0.003) \\
\text { Moderate/severe PVL }(3.4 \% \text { vs. } 1.5 \%, P \text { equivalence }=0.0001) \\
\text { PPI }(23.0 \% \text { vs. } 19.2 \%, P \text { equivalence }=0.06)\end{array}$ \\
\hline $\begin{array}{l}\text { France-TAVI } \\
\text { (2019) }\end{array}$ & $\begin{array}{l}\text { Observational study } \\
\text { (propensity matching) }\end{array}$ & 20 months & 12141 & $\begin{array}{l}\text { BE TAVI associated with lower incidence of: } \\
\text { Moderate PVR ( } 8.3 \% \text { vs. } 15.8 \%, P<0.0001) \\
\text { In hospital mortality }(4.2 \% \text { vs. } 5.6 \%, P=0.01) \\
2 \text { years mortality }(26.6 \% \text { vs. } 29.8 \%, P=0.003)\end{array}$ \\
\hline $\begin{array}{l}\text { Deharo et al. }{ }^{[12]} \\
(2020)\end{array}$ & $\begin{array}{l}\text { Observational study } \\
\text { (propensity matching) }\end{array}$ & 12 months & 20918 & $\begin{array}{l}\text { BE TAVI associated with lower incidence of: } \\
\text { All-cause death }(14.4 \% \text { vs. } 16.4 \%, P=0.005) \\
\text { Cardiovascular death }(6.4 \% \text { vs. } 7.9 \%, P=0.002) \\
\text { PPI }(20.5 \% \text { vs. } 25.9 \%, P<0.0001) \\
\text { Rehospitalization for HF }(19.5 \% \text { vs. } 23.2 \%, P<0.0001)\end{array}$ \\
\hline
\end{tabular}

AR: Aortic regurgitation; BE: balloon expandable; BVF: bioprosthetic valve failure; CV: cardiovascular; HF: heart failure; PPI: permanent pacemaker implantation; PVL: paravalvular leak; PVR: paravalvular regurgitation; RCT: randomized controlled trial; SE: self expandable.

after five years of follow-up, where the two types of prostheses were not different in CV death, strokes, rehospitalization for heart failure, and even paravalvular regurgitation. Moderate to severe structural valve deterioration was more frequent with $\mathrm{BE}$ prostheses, and SE showed lower mean gradient, also due to a larger valve area ${ }^{[28]}$.

Two large multicenter real-world registries recently suggested better performances of BE prostheses compared to $\mathrm{SE}^{[9,12]}$. These registries respectively compared 12,141 patients treated with $\mathrm{SE}$ (CoreValve) or BE (SAPIEN XT and SAPIEN 3) prostheses between 2013 and 2015, and 31,113 patients who implanted Sapien 3 (SE) vs. Evolut R (BE) between 2014 and 2018. Independently from valve generation, BE prostheses showed lower incidence of all-cause and CV mortality after one and two years of follow-up, less rehospitalization for heart failure, and were associated with lower PPI after procedure and less more-thanmoderate PVL [Table 1].

The survival benefit in favor of BE prostheses observed in the FRANCE-TAVI registry analysis may thus be attributed more to the patient characteristics and surgical risk than to the type of prostheses implanted. Indeed, even though multivariable matching was done, the nonrandomized design of the analysis left a risk of residual confounding factors. Transcatheter valve selection was driven by physician preference, often based on the presence of unfavorable anatomic factors with the SE prosthesis. Moreover, patient and procedural characteristics such as surgical risk, mean gradient, valve area, degree of calcifications, and PVL were not included in the analysis. In addition, patients enrolled in these registries were all high-risk patients, preventing to draw a definite answer in a low surgical risk population.

However, these registries have raised a debate on which TAVI technology performs better for each patient, and future studies with longer follow-up are needed to compare latest generation devices and analyze 
patient comorbidities, anatomical factors, and procedural concerns in order to understand which type of prostheses is best for the single patient.

\section{ASSESSING VALVE FAILURE}

In the last years, many studies have assessed long-term outcomes of transcatheter and surgical aortic valve replacement in not conclusive ways ${ }^{[29-32]}$, and some of them (especially for surgical prosthesis) have considered as outcomes only all-cause mortality and the need of reintervention, underestimating the complexity of BVD, a multifactorial phenomenon which needs a more complete definition. BVD has historically been divided into SVD (structural valve deterioration, including irreversible intrinsic changes of the prosthetic valve structure), NSVD (non-structural valve deterioration, including irreversible intra- or para-prosthetic regurgitation, prosthesis malposition, and patient-prosthesis mismatch), valve thrombosis, and endocarditis (which can be potentially reversible) ${ }^{[33]}$.

Current data available for long-term durability of surgical bioprostheses show that SVD (defined as severe aortic stenosis or regurgitation) occurs in $21 \%$ of patients at 15 years and $51 \%$ at 20 years ${ }^{[31]}$. However, these data cannot be translated to TAVI prostheses because of some substantial differences between surgical and transcatheter prostheses, such as aortic calcification, valve geometry and morphology, type of expansion, and patient-prosthesis mismatch. Besides, long-term durability of TAVI prostheses is becoming increasingly important, with the extension of this procedure to younger patients with a lower surgical risk, which has led to the necessity of a standardized definition of valve and patient-oriented durability outcomes, including echocardiographic findings.

A first standardized definition of SVD was provided by a consensus paper published in 2017. SVD was divided into morphological disfunction (based on imaging findings regarding frame and leaflets function, integrity, and structure) and hemodynamic disfunction (based on echocardiographic findings). Moderatesevere hemodynamic SVD was defined as: mean gradient $>20 \mathrm{mmHg}$ and/or increase in mean gradient $>10 \mathrm{mmHg}$ from three months post-procedure and/or more-than-mild aortic regurgitation (AR) either new or worsening from three months post-procedure ${ }^{[33]}$. One year later, Dvir et al. ${ }^{[34]}$ suggested a new nondichotomous classification of SVD, assessed with combined hemodynamic and morphological parameters. SVD was defined as a gradual process, which typically develops over years, and four stages of severity were proposed.

Long-term data regarding BVD are still discordant and are available only for first-generation devices, due to the shorter follow up available of latest generation devices.

The NOTION trial with an available follow up of six years evaluated the long-term durability of SE prostheses in this category of patients. After six years of follow-up, hemodynamic parameters were better with TAVI compared to surgery, with wider effective orifice area (EOA) $\left(1.53 \mathrm{~cm}^{2} v s .1 .16 \mathrm{~cm}^{2}, P=0.002\right)$ and lower mean aortic gradient $(9.9 \mathrm{mmHg} v s .14 .7 \mathrm{mmHg}, P=0.001)^{[8]}$. These findings reflect a minor incidence of severe prosthesis patient mismatch (PPM), probably due to a more favorable design of SE prostheses with a supra-annular leaflet positioning that provides a larger opening area compared with BE prostheses, whose leaflet are intra-annular. SVD occurred more frequently in SAVR, but TAVI prostheses had a more than ten times higher rates of moderate to severe PVL (20.9\% vs. $1.5 \%, P=0.001)$, with $45.9 \%$ vs. $16.7 \%$ of mild PVL after five years ${ }^{[18]}$. These data should be prudently analyzed, considering the use of first-generation SE prostheses (without outer sealing skirt) and that CT scanning for aortic annulus sizing was not introduced when the NOTION trial started.

Some recently published trials assessed BVD for latest generation devices showing, for BE prostheses compared to SAVR, no significant difference in moderate to severe PVL (0.6\% vs. $0.5 \%)$ and prosthetic 
Table 2. Incidence of PVL between TAVI and SAVR in low surgical risk patients

\begin{tabular}{lcccc}
\hline Trial & Type of valve & Lenght of follow up & Mild PVL (TAVI vs. SAVR) & Moderate severe PVL (TAVI vs. SAVR) \\
\hline PARTNER 3 & BE & 1 year & $29.4 \%$ vs. $2.1 \%$ & $0.6 \%$ vs. $0.5 \%$ \\
EVOLUT LOW RISK & SE & 1 year & $25.7 \%$ vs. $1.6 \%$ & $5.7 \%$ vs. $0 \%$ \\
NOTION & SE & 5 years & $45.9 \%$ vs. $16.7 \%$ & $20.9 \%$ vs. $1.5 \%$ \\
\hline
\end{tabular}

PVL: Paravalvular leaks; TAVI: transcatheter aortic valve implantation; SAVR: surgical aortic valve replacement; BE: balloon expandable; SE: self expandable.

gradients, after one year of follow-up. Mild PVL, however, was significantly higher with transcatheter devices $(29.4 \% \text { vs. } 2.1 \%)^{[6]}$.

Similar results were also observed with SE devices, with a lower mean aortic gradient and a larger EOA at one year for TAVI, as well as lower rates of PPM. Again, mild PVL was more frequent in the TAVI group $(25.7 \%$ vs. $1.6 \%)$ with a trend of higher rates of moderate PVL [5.7\% vs. $0 \%$, CI: $(-0.7,12.1)]$ [Table 2].

Regarding a direct comparison of BE $v s$. SE prostheses, the SOLVE TAVI trial showed at 30 days a noninferiority between the two groups for mean gradient, EOA, and rates of $\mathrm{PVL}^{[26]}$. This was in contrast with the results of the CHOICE trial, which evidenced, for first-generation devices, a more frequent moderate/severe paravalvular regurgitation for SE prostheses compared to BE. This was mostly related to periprocedural outcomes, because no significant changes were observed in PVL rates between 30 days and one year, and after five years of follow-up this difference was no longer significant ${ }^{[27,28]}$.

However, analyzing the data from PARTNER 3 and Evolut Low Risk trials, more-than-mild PVL seems to be more frequent in SE than in BE devices (5.7\% vs. $0.6 \%$ ), and it was confirmed by the large recently published FRANCE-TAVI registry ${ }^{[6-9]}$. In this registry, moderate to severe PVL occurred in $15.5 \%$ of patients implanted with SE TAVI compared $8.3 \%$ with BE TAVI, and this was correlated with a higher risk of two years all-cause and CV mortality, which was higher in SE prostheses. With the release of newer generation valves in the last year of the study, the difference in PVL rates further increased. While the SAPIEN 3 prosthesis, thanks to an additional antileak skirt, reduced PVL rates from $9 \%$ to $6.2 \%$ compared with SAPIEN XT, the same did not occurr with newer generation SE valves (from $15.9 \%$ to $14.8 \%$ ) $^{[9]}$.

The latest Medtronic prosthesis, Evolut Pro, with an additional pericardial wrap, is supposed to reduce incidence of PVL, but a recent nonrandomized small study did not show any significant difference between Evolut Pro and Evolut ${ }^{[35]}$.

The difference in PVL rates between different TAVI technologies and SAVR is a crucial topic, because moderate to severe PVL is related with higher mortality even at mid-term follow-up ${ }^{[9]}$.

In this context, the technical aspect of TAVI procedure can also have a relevant role. For example direct TAVI without pre-dilatation has recently emerged as a feasible and safe alternative option, and his impact on BVD is another matter of debate. This approach, compared with the pre-balloon-aortic valvuloplasty (BAV) one, showed similar periprocedural outcomes and similar short-term PVL rates ${ }^{[36-38]}$. However no long-term results are available and the effects on long term durability of not performing preprocedural BAV are still unknown, with concerns related to potentially suboptimal device apposition and expansion.

Long-term reduction of moderate to severe PVL on newer generation transcatheter prostheses, along with the role of mild PVL on long-term outcomes, still needs to be clarified. Some evidence may suggest no differences in mortality between none or mild $\mathrm{PVL}^{[39]}$, but it is based on short- and mid-term follow-up and patients at intermediate and high surgical risk. According to FRANCE2-TAVI registry results, instead, mild 
PVL is associated with an additional $13 \%-18 \%$ increase of death ${ }^{[9]}$. At long-term follow-up, it may have a great prognostic impact, especially because up to $30 \%$ of low-risk cases develop mild PVL at one year ${ }^{[6]}$.

Randomized controlled trials with longer follow-up are needed to provide meaningful echocardiographic data at least at 10 years.

However, considering the vertiginous technologic improvement of transcatheter devices, long-term data on current prostheses will be obsolete in ten years, leaving literature always one step behind technology as far as long-term follow-up is concerned.

\section{LONG-TERM DURABILITY OF TAVI, FROM BENCH TO BEDSIDE}

To date, long-term durability data of surgical bioprostheses are largely available. Despite being discordant in BVD outcomes definition and differing according to the type of valve, current evidence suggests that the ten-year survival is more than $55 \%$ in patients with mean age of 70 years ${ }^{[40]}$. These results are even better in younger patients (60-70 years) and when surgery is less complicated, especially when SAVR is alone without concomitant CABG. Incidence of SVD (death, re-operation, and clinical investigation due to suspect of SVD) after SAVR seems to be $10 \%$ at ten-year follow-up ${ }^{[41]}$.

As far as transcatheter prostheses are concerned, longer-term data are available only for high surgical risk patients ${ }^{[42,28]}$ and first-generation devices ${ }^{[18]}$. Recently published studies, enrolling low surgical risk patients treated with latest generation prostheses, have only a short-term follow-up.

This complex scenario has pushed many authors to assess the long-term durability of the latest-generation devices in low-risk patients using hypothetical simulation models.

In 2015, Martin and Sun suggested, using a complex simulation model, that TAVI durability can be limited to 7-8 years even in the case of an optimal valve deployment. This was due to higher leaflet stress and strain in TAVI compared with SAVR, but these results were related only to first-generation prostheses ${ }^{[43]}$.

Another interesting simulation model, which compared PARTNER 3 TAVI and SAVR cohorts, was recently published by Tam and colleagues. The mean age of patients was 73 years, and all patients were at low surgical risk (mean STS 3.2\%). Primary outcome was death or need of re-operation, and patients were followed up until one of these events occurred, or until the end to the pre-specified 40-year follow-up.

The authors noticed a significant difference in life expectancy between the two cohorts only when TAVI durability was worse than $70 \%$ compared with SAVR. It means that transcatheter valves needed to be only $30 \%$ as durable as current surgical valves to guarantee similar life expectancy. However, this was not observed for 40 to 60-year-old patients, where even 30\%-50\% durability gaps were related to decreased life expectancy. Re-operation mortality doubled the predefined STS score, but the overall impact on life expectancy was minimal because in most cases the valve outlived the patient (mean age was 73 years old) and no re-operation was needed ${ }^{[44]}$.

In summary, according to some recent simulation models, transcatheter valves durability should not influence the clinical decision when low surgical risk patients are elderly, such as those in recent RCTs. On the other hand, in younger patients, the choice between SAVR and TAVI should be more carefully evaluated by the heart team. In fact, implanting transcatheter prostheses in 65 to 70 -year-old patients with average life expectancy will carry higher risk of re-operation, with a potentially important impact on mortality. 


\section{THERAPEUTIC OPTION FOR VALVE FAILURE: TRANSCATHETER VALVE-IN-VALVE}

Current management of TAV failure, both peri-procedural and after discharge, mainly consists in transcatheter Valve-in-Valve intervention or SAVR.

Initially, ViV TAVI was performed after a failure of expansion of the first aortic prosthesis implanted in order to decrease the aortic regurgitation ${ }^{[45]}$, but, nowadays, with the improvement of operator skill and device technology, it is also used as a valid alternative to redo SAVR in degenerated bioprostheses, both transcatheter and surgical.

Little evidence is available on this topic, and most is related to TAVI in SAVR procedures ${ }^{[46,47]}$. Compared to redo SAVR, ViV TAVI seems to have better short-term outcomes ${ }^{[48,49]}$ even if performed in patients with an increased surgical risk, and it is related with less dialysis and PPI, especially when BE valves are used $^{[50]}$. However, some concerns about long-term outcomes and especially re-hospitalizations still exist ${ }^{[45]}$. The results from a small cohort (365 patients) of ViV high-risk patients from the PARTNER trial ${ }^{[51]}$ show $67 \%$ survival at three years, and similar rates were observed by a larger international registry ${ }^{[52]}$, with lower survival in small-failed bioprostheses (internal diameter $<20 \mathrm{~mm}$ ) compared with larger ones.

A dangerous complication regarding TAVI ViV is acute coronary obstruction. This is related to high mortality and, compared with TAVI procedures, occurs threefold more frequently during and after TAVI $\mathrm{ViV}(2 \%-3 \% v s .<1 \%)^{[47]}$. The therapeutic option to face this complication could be the preventive stenting or wiring of the threatened coronary artery, but this technique carries higher rates of stent compression and thrombosis ${ }^{[53,54]}$. An interesting solution has been recently proposed by the BASILICA trial, which obtained $100 \%$ freedom from coronary artery obstruction, in which it was proposed to lacerate the bioprosthetic or native valve scallops immediately before the placement of the prostheses ${ }^{[55,56]}$. Although encouraging, this technique requires prospective trials to be further analyzed and to date has never been tested for TAVI in TAVI intervention.

As far as TAVI in TAVI is concerned, this procedure appears to be safe, with $85.1 \%$ survival after almost two years ${ }^{[57]}$. However, most of the available evidence includes intraprocedural rescue TAVI in TAVI ${ }^{[58]}$ and to date no long-term study are available to assess durability of this intervention. TAVI in TAVI may be related with better survival compared with TAVI in SAVR, due to higher mean EOA and less PPM after TAVI than after SAVR. On the other hand, special attention and evaluation of coronary artery ostium must be assessed because of a potentially increased risk of coronary obstruction, especially when SE prostheses with wider supra-annular area are implanted.

Along with the widening of TAVI indications in low surgical risk patients with lower age, the number of transcatheter valves implanted is rapidly growing, and this will increase the amount of TAVI ViV procedures for failed TAVI in the next years. In this scenario, a careful assessment of the prognostic impact of TAVI in TAVI is strongly required. Future studies are needed to clarify this complex topic and compare the technical aspects of TAVI in TAVI to TAVI in SAVR.

\section{CONCLUSIONS}

The indications for TAVI have been progressively extended to all spectrum of surgical risk patients, due to the non-inferiority compared with surgery at short- and mid-term follow-up. Even if durability seems to be similar between TAVI and SAVR, to date, long-term data are lacking and only computed simulation models can assess long-term durability of these platforms. In this context, comparable rates of PPM and larger EOA could be encouraging findings, but TAVI still carries higher rate of NSVD, such as mild PVL, whose prognostic impact is unclear. 
According to these results, the implantation of TAVI in elderly patients regardless of surgical risk seems reasonable, because in such cohorts transcatheter platforms should outlive the patient. However, although the mean age of TAVI candidates has lowered by 10 years, patients included in low surgical risk RCTs are still over 70 years old and no data are provided about durability rates in younger patients. To date, performing TAVI in younger patients with longer average life expectancy still might be premature, due to increased likelihood of future re-operation with worse prognostic impact.

\section{DECLARATIONS}

\section{Author's contribution}

Article conception and design: Marengo G, Elia E

Acquisition and analysis of bibliographic information: Marengo G, Elia E, Bruno F

Drafting of the manuscript: Marengo G, Bruno F, Franchin L

Critical revision and final approval of the manuscript: Piroli F, De Filippo O, De Ferrari GM, Conrotto F, D’Ascenzo F

\section{Availability of data and materials}

Not applicable.

\section{Financial support and sponsorship}

None.

\section{Conflicts of interest}

All authors declared that there are no conflicts of interest.

\section{Ethical approval and consent to participate}

Not applicable.

\section{Consent for publication}

Not applicable.

\section{Copyright}

(c) The Author(s) 2021.

\section{REFERENCES}

1. Leon MB, Smith CR, Mack M, et al. Transcatheter aortic-valve implantation for aortic stenosis in patients who cannot undergo surgery. $N$ Engl J Med 2010;363:1597-607.

2. Smith CR, Leon MB, Mack MJ, et al; PARTNER Trial Investigators. Transcatheter versus surgical aortic-valve replacement in high-risk patients. N Engl J Med 2011;364:2187-98.

3. Leon MB, Smith CR, Mack MJ, et al; PARTNER 2 Investigators. Transcatheter or surgical aortic-valve replacement in intermediate-risk patients. N Engl J Med 2016;374:1609-20.

4. Reardon MJ, Van Mieghem NM, Popma JJ, et al; SURTAVI Investigators. Surgical or transcatheter aortic-valve replacement in intermediate-risk patients. $N$ Engl J Med 2017;376:1321-31.

5. Rahhab Z, El Faquir N, Tchetche D, et al. Expanding the indications for transcatheter aortic valve implantation. Nat Rev Cardiol 2020;17:75-84.

6. Mack MJ, Leon MB, Thourani VH, et al; PARTNER 3 Investigators. Transcatheter aortic-valve replacement with a balloon-expandable valve in low-risk patients. N Engl J Med 2019;380:1695-705.

7. Popma JJ, Deeb GM, Yakubov SJ, et al; Evolut Low Risk Trial Investigators. Transcatheter aortic-valve replacement with a selfexpanding valve in low-risk patients. N Engl J Med 2019;380:1706-15.

8. Søndergaard L, Ihlemann N, Capodanno D, et al. Durability of transcatheter and surgical bioprosthetic aortic valves in patients at lower surgical risk. J Am Coll Cardiol 2019;73:546-53.

9. Van Belle E, Vincent F, Labreuche J, et al. Balloon-expandable versus self-expanding transcatheter aortic valve replacement: a propensitymatched comparison from the FRANCE-TAVI registry. Circulation 2020;141:243-59. 
10. Kodali S, Pibarot P, Douglas PS, et al. Paravalvular regurgitation after transcatheter aortic valve replacement with the Edwards sapien valve in the PARTNER trial: characterizing patients and impact on outcomes. Eur Heart $J$ 2015;36:449-56.

11. Piroli F, Franchin L, Bruno F, De Filippo O, D’Ascenzo F, Conrotto F. New advances in the prevention of transcatheter aortic valve implantation failure: current and future perspectives. Kardiol Pol 2020;78:842-9.

12. Deharo P, Bisson A, Herbert J, et al. Impact of sapien 3 balloon-expandable versus evolut $r$ self-expandable transcatheter aortic valve implantation in patients with aortic stenosis: data from a nationwide analysis. Circulation 2020;141:260-8.

13. Conrotto F, D'Ascenzo F, Giordana F, et al. Impact of diabetes mellitus on early and midterm outcomes after transcatheter aortic valve implantation (from a multicenter registry). Am J Cardiol 2014;113:529-34.

14. D'Ascenzo F, Gonella A, Moretti C, et al. Gender differences in patients undergoing TAVI: a multicentre study. EuroIntervention 2013;9:367-72.

15. Conrotto F, D’Ascenzo F, Presbitero P, et al. Effect of gender after transcatheter aortic valve implantation: a meta-analysis. Ann Thorac Surg 2015;99:809-16.

16. Adams DH, Popma JJ, Reardon MJ, et al; U.S. CoreValve Clinical Investigators. Transcatheter aortic-valve replacement with a selfexpanding prosthesis. N Engl J Med 2014;370:1790-8.

17. Thyregod HG, Steinbrüchel DA, Ihlemann N, et al. Transcatheter versus surgical aortic valve replacement in patients with severe aortic valve stenosis: 1-year results from the all-comers NOTION randomized clinical trial. J Am Coll Cardiol 2015;65:2184-94.

18. Thyregod HGH, Ihlemann N, Jørgensen TH, et al. Five-year clinical and echocardiographic outcomes from the Nordic Aortic Valve Intervention (NOTION) randomized clinical trial in lower surgical risk patients. Circulation 2019.

19. Biasco L, Ferrari E, Pedrazzini G, et al. Access sites for TAVI: patient selection criteria, technical aspects, and outcomes. Front Cardiovasc Med 2018;5:88.

20. Virtanen MPO, Eskola M, Jalava MP, et al. Comparison of outcomes after transcatheter aortic valve replacement vs surgical aortic valve replacement among patients with aortic stenosis at low operative risk. JAMA Netw Open 2019;2:e195742.

21. Rosato S, Santini F, Barbanti M, et al; OBSERVANT Research Group. Transcatheter aortic valve implantation compared with surgical aortic valve replacement in low-risk patients. Circ Cardiovasc Interv 2016;9:e003326.

22. Barbanti M, Tamburino C, D’Errigo P, et al; OBSERVANT Research Group. Five-year outcomes of transfemoral transcatheter aortic valve replacement or surgical aortic valve replacement in a real world population. Circ Cardiovasc Interv 2019;12:e007825.

23. Barbanti M, Costa G, Zappulla P, et al. Incidence of long-term structural valve dysfunction and bioprosthetic valve failure after transcatheter aortic valve replacement. J Am Heart Assoc 2018;7:e008440.

24. Blackman DJ, Saraf S, MacCarthy PA, et al. Long-term durability of transcatheter aortic valve prostheses. J Am Coll Cardiol 2019;73:537-45

25. Testa L, Latib A, Brambilla N, et al. Long-term clinical outcome and performance of transcatheter aortic valve replacement with a selfexpandable bioprosthesis. Eur Heart J 2020;41:1876-86.

26. Thiele H, Kurz T, Feistritzer HJ, et al. Comparison of newer generation self-expandable vs. balloon-expandable valves in transcatheter aortic valve implantation: the randomized SOLVE-TAVI trial. Eur Heart J 2020;41:1890-9.

27. Abdel-Wahab M, Mehilli J, Frerker C, et al; CHOICE investigators. Comparison of balloon-expandable vs self-expandable valves in patients undergoing transcatheter aortic valve replacement: the CHOICE randomized clinical trial. JAMA 2014;311:1503-14.

28. Abdel-Wahab M, Landt M, Neumann FJ, et al; CHOICE Investigators. 5-year outcomes after TAVR with balloon-expandable versus selfexpanding valves: results from the CHOICE randomized clinical trial. JACC Cardiovasc Interv 2020;13:1071-82.

29. Sénage T, Le Tourneau T, Foucher Y, et al. Early structural valve deterioration of Mitroflow aortic bioprosthesis: mode, incidence, and impact on outcome in a large cohort of patients. Circulation 2014;130:2012-20.

30. Mohammadi S, Tchana-Sato V, Kalavrouziotis D, et al. Long-term clinical and echocardiographic follow-up of the Freestyle stentless aortic bioprosthesis. Circulation 2012;126:S198-204.

31. Bourguignon T, Bouquiaux-Stablo AL, Candolfi P, et al. Very long-term outcomes of the Carpentier-Edwards Perimount valve in aortic position. Ann Thorac Surg 2015;99:831-7.

32. Johnston DR, Soltesz EG, Vakil N, et al. Long-term durability of bioprosthetic aortic valves: implications from 12,569 implants. Ann Thorac Surg 2015;99:1239-47.

33. Capodanno D, Petronio AS, Prendergast B, et al. Standardized definitions of structural deterioration and valve failure in assessing long-term durability of transcatheter and surgical aortic bioprosthetic valves: a consensus statement from the European Association of Percutaneous Cardiovascular Interventions (EAPCI) endorsed by the European Society of Cardiology (ESC) and the European Association for Cardio-Thoracic Surgery (EACTS). Eur Heart J 2017;38:3382-90.

34. Dvir D, Bourguignon T, Otto CM, et al; VIVID (Valve in Valve International Data) Investigators. Standardized Definition of structural valve degeneration for surgical and transcatheter bioprosthetic aortic valves. Circulation 2018;137:388-99.

35. Hellhammer K, Piayda K, Afzal S, et al. The latest evolution of the medtronic corevalve system in the era of transcatheter aortic valve replacement: matched comparison of the evolut PRO and evolut R. JACC Cardiovasc Interv 2018;11:2314-22.

36. Bijuklic K, Haselbach T, Witt J, et al. Increased risk of cerebral embolization after implantation of a balloon-expandable aortic valve without prior balloon valvuloplasty. JACC Cardiovasc Interv 2015;8:1608-13.

37. Toutouzas K, Benetos G, Voudris V, et al. Pre-dilatation versus no pre-dilatation for implantation of a self-expanding valve in all comers undergoing TAVR: the DIRECT trial. JACC Cardiovasc Interv 2019;12:767-77.

38. Conradi L, Schaefer A, Seiffert M, et al. Transfemoral TAVI without pre-dilatation using balloon-expandable devices: a case-matched analysis. Clin Res Cardiol 2015;104:735-42. 
39. Pibarot P, Hahn RT, Weissman NJ, et al. Association of paravalvular regurgitation with 1-year outcomes after transcatheter aortic valve replacement with the SAPIEN 3 valve. JAMA Cardiol 2017;2:1208-16.

40. Forcillo J, Pellerin M, Perrault LP, et al. Carpentier-Edwards pericardial valve in the aortic position: 25-years experience. Ann Thorac Surg 2013;96:486-93.

41. Nishida T, Tominaga R. A look at recent improvements in the durability of tissue valves. Gen Thorac Cardiovasc Surg 2013;61:182-90.

42. Kapadia SR, Leon MB, Makkar RR, et al. 5-year outcomes of transcatheter aortic valve replacement compared with standard treatment for patients with inoperable aortic stenosis (PARTNER 1): a randomised controlled trial. Lancet 2015;385:2485-91.

43. Martin C, Sun W. Comparison of transcatheter aortic valve and surgical bioprosthetic valve durability: A fatigue simulation study. $J$ Biomech 2015;48:3026-34.

44. Tam DY, Wijeysundera HC, Naimark D, et al. Impact of transcatheter aortic valve durability on life expectancy in low-risk patients with severe aortic stenosis. Circulation 2020;142:354-64.

45. Deharo P, Bisson A, Herbert J, et al. Transcatheter valve-in-valve aortic valve replacement as an alternative to surgical re-replacement. $J$ Am Coll Cardiol 2020;76:489-99.

46. Tchétché D, Chevalier B, Holzhey D, et al; VIVA Investigators. TAVR for failed surgical aortic bioprostheses using a self-expanding device: 1-year results from the prospective VIVA postmarket study. JACC Cardiovasc Interv 2019;12:923-32.

47. Giordana F, Bruno F, Conrotto F, et al. Incidence, predictors and outcomes of valve-in-valve TAVI: A systematic review and metaanalysis. Int J Cardiol 2020;316:64-9.

48. Tam DY, Vo TX, Wijeysundera HC, Dvir D, Friedrich JO, Fremes SE. Transcatheter valve-in-valve versus redo surgical aortic valve replacement for the treatment of degenerated bioprosthetic aortic valve: A systematic review and meta-analysis. Catheter Cardiovasc Interv 2018;92:1404-11.

49. Hirji SA, Percy ED, Zogg CK, et al. Comparison of in-hospital outcomes and readmissions for valve-in-valve transcatheter aortic valve replacement vs. reoperative surgical aortic valve replacement: a contemporary assessment of real-world outcomes. Eur Heart $J$ 2020;41:2747-55.

50. Lee HA, Chou AH, Wu VC, et al. Balloon-expandable versus self-expanding transcatheter aortic valve replacement for bioprosthetic dysfunction: A systematic review and meta-analysis. PLoS One 2020;15:e233894.

51. Webb JG, Mack MJ, White JM, et al. Transcatheter Aortic Valve Implantation Within Degenerated Aortic Surgical Bioprostheses: PARTNER 2 Valve-in-Valve Registry. J Am Coll Cardiol 2017;69:2253-62.

52. Bleiziffer S, Simonato M, Webb JG, et al. Long-term outcomes after transcatheter aortic valve implantation in failed bioprosthetic valves. Eur Heart $J$ 2020;41:2731-42.

53. Abramowitz Y, Chakravarty T, Jilaihawi H, et al. Clinical impact of coronary protection during transcatheter aortic valve implantation: first reported series of patients. EuroIntervention 2015;11:572-81.

54. Jabbour RJ, Tanaka A, Finkelstein A, et al. Delayed coronary obstruction after transcatheter aortic valve replacement. J Am Coll Cardiol 2018;71:1513-24.

55. Khan JM, Dvir D, Greenbaum AB, et al. Transcatheter laceration of aortic leaflets to prevent coronary obstruction during transcatheter aortic valve replacement: concept to first-in-human. JACC Cardiovasc Interv 2018;11:677-89.

56. Khan JM, Greenbaum AB, Babaliaros VC, et al. The BASILICA trial: prospective multicenter investigation of intentional leaflet laceration to prevent TAVR coronary obstruction. JACC Cardiovasc Interv 2019;12:1240-52.

57. Barbanti M, Webb JG, Tamburino C, et al. Outcomes of redo transcatheter aortic valve replacement for the treatment of postprocedural and late occurrence of paravalvular regurgitation and transcatheter valve failure. Circ Cardiovasc Interv 2016;9:e003930.

58. Makkar RR, Jilaihawi H, Chakravarty T, et al. Determinants and outcomes of acute transcatheter valve-in-valve therapy or embolization: a study of multiple valve implants in the U.S. PARTNER trial (Placement of AoRTic TraNscathetER Valve Trial Edwards SAPIEN Transcatheter Heart Valve). J Am Coll Cardiol 2013;62:418-30. 